
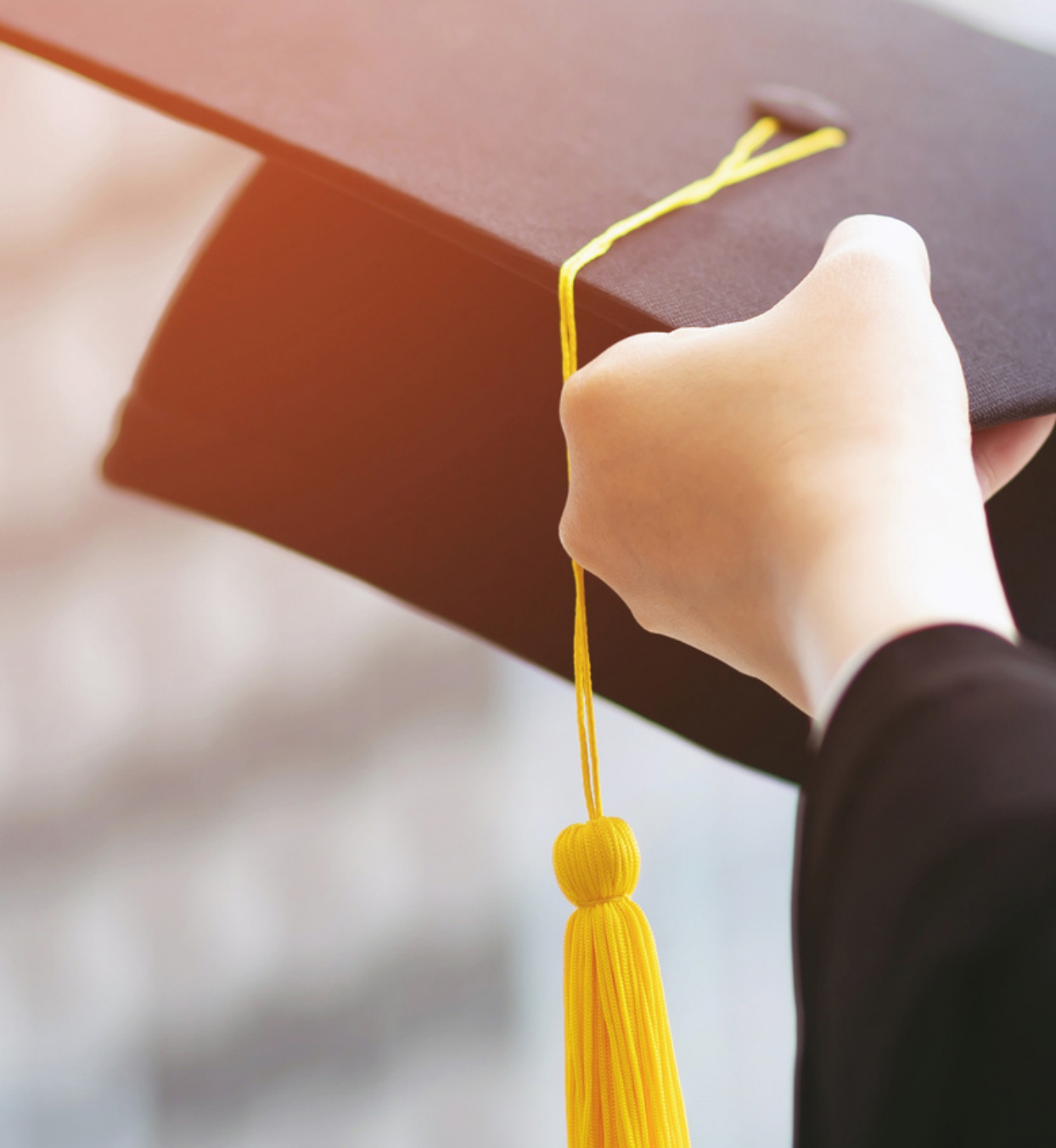

\title{
Modalidades de titulación en las carreras universitarias de salud
}

ISBN: 978-9942-846-05-1

\section{Autores:}

- Roberth Olmedo Zambrano Santos Universidad Estatal del Sur de Manabí.

- Aida Monserrate Macías Alvia Universidad Estatal del Sur de Manabí.

- Bárbara Miladys Placencia López Universidad Estatal del Sur de Manabí.

- Jaqueline Beatriz Delgado Molina Universidad Estatal del Sur de Manabí.

- Sandra María Linares Giler Universidad Técnica de Manabí.

- Zulbey Chiquinquirá Rivero de Rodríguez Universidad Técnica de Manabí.

- Carmen Natacha Pérez Cardoso Universidad Técnica de Manabí.
- María del Rosario Herrera Velásquez Universidad Estatal del Sur de Manabí.

- Adis Anicia Luna Báez Universidad Estatal del Sur de Manabí.

- Luis Adrián Loor Cedeño Universidad Estatal del Sur de Manabí.

- María Liliana Calderón Macías Universidad Estatal del Sur de Manabí.

- Johanna Mabel Sánchez Rodríguez Universidad Laica Eloy Alfaro de Manabí. Universidad Estatal del Sur de Manabí.

- Milton René Espinoza Lucas Universidad Laica Eloy Alfaro de Manabí.

- Jesús Yubagni Rezabala Villao Universidad Laica Eloy Alfaro de Manabí.
- Addys Parra Cruz Universidad San Gregorio de Portoviejo.

- Nely Antonieta San Andrés Plúa Universidad San Gregorio de Portoviejo.

- Shirley Ximena Arteaga Espinoza Universidad Laica Eloy Alfaro de Manabí.

- Luz Amarilis Martin Moya Universidad San Gregorio de Portoviejo.

- Dolores Isabel Chavarría Cedeño Universidad Técnica de Manabí.

- María Magaly Scott Álava Universidad Técnica de Manabí.

- Franklin Antonio Vite Solórzano Universidad Técnica de Manabí.

- Maribel del Rocío García Macías Universidad Técnica de Manabí. 